\title{
The Study of the Effect of Educational Level of Students and English Language Teachers' Awareness on True and False Cognates in Iran
}

\author{
Javad Gholami, Parviz Alavinia, Siros Izadpanah \\ Urmia University, Urmia, Iran
}

\begin{abstract}
The ability to speak two languages in the non-English-speaking countries is a remarkable achievement. There is a good reason to believe that bilingualism is the norm for the majority of people in the world, because $70 \%$ of the earth's population are supposed to be bilingual or multilingual. Our purpose of the study was to determine the participants' awareness of using true and false cognate words of L1 (the first language) \& L2 (the second language) in learning English. Three hundred and eighty-five selected people from 3,789 statistical population participated in 2014-2015 at three levels of A.D., B.A., and M.A. of Islamic Azad University as well as teachers of English in English educational institutions in Zanjan (Iran). Each educational level was considered as one category with the total sample calculated by using Kokran Formula, and the amount of each category was determined by using appropriate proportion and randomized categorical sampling method. The participants' age was between from 18 to 52 , with a mean age of 29 years. The materials were 45 words of true and false cognate's words from 500 words by doing CVR (content validity ratio) and CVI (content validity index) (Lawshe's table with the index of $88 \%$ and $82 \%$ respectively) for being reliable and valid. ANOVA (Analysis of variance) was used for studying the effect of educational level on the rate of awareness. In other words, the awareness level has been compared in different educational levels. The results of Dankan test show that: There is no significant difference between the awareness of A.D., B.A., and M.A. levels, but there is a significant difference between the level of awareness of teachers group and the other groups (in true cognate words) and for false cognate words, there is no significant difference between the level of awareness of the four groups in this regard.
\end{abstract}

Keywords: awareness, educational level, false and true cognate words, L2 structural relationship

\section{Introduction}

Learning a new word in a foreign language occasionally consists of connecting a new lexical form with an idea in our mind which is associated to the comparable word in the mother language. The way that this topography is recognized and the way it changes during the times are serious subjects in Second Language

Javad Gholami, assistant professor, Ph.D., Department of English Language and Literature, Faculty of Humanities and Letters, Urmia University.

Parviz Alavinia, assistant professor, Ph.D., Department of English Language and Literature, Faculty of Humanities and Letters, Urmia University.

Siros Izadpanah, Ph.D. candidate, Department of English Language and Literature, Faculty of Humanities and Letters, Urmia University. 
Acquisition (SLA). In spite of the number of studies ripened to reply these queries (e.g., Basnight \& Altarriba, 2007; Bassetti \& Cook, 2011; Bultena, Dijkstra, \& van Hell, 2014; Casaponsa, Antón, Pérez, \& Duñabeitia, 2015; Ferré, Sánchez-Casas, \& Guasch, 2006; Linck \& Kroll, 2008; Sunderman \& Kroll, 2006), these are still objects of controversy.

Cross-linguistic cognates give particular foresight in comprehending the bilingual glossary, as the intent and relating lexical demonstration of cognates covers the two language of a bilingual (Dijkstra, Miwa, Brummelhuis, Sappelli, \& Baayen, 2010). Cognates are words that contribute to phonological or spelling form and are usually related in definition even though all of cognates are not always translation tantamount (Hall, Newbrand, Ecke, Sperr, Marchand, \& Hayes, 2009), for instance, the cognate pair in Persian and English "tundr-thunder", similar morphology (i.e., vocabulary form) the similar phonology (i.e., sounds), and the similar orthography (i.e., written form). This coverage has been indication as the evidence of privileges for cognates over other kinds in accomplishing the processing, and producing in both bilingual (Kennison, Fernandez, \& Bowers, 2014) and adults of monolingual (Kroll \& Tokowicz, 2005). Learners who use cognate resemblances and have better performance on cognates rather than noncognates are thought to show the cognate facilitation effects, or advantage of cognate (Peeters, Dijkstra, \& Grainger, 2013).

The cognate simplification effect has been certificated by maximum precision on performance on cognates rather than other word types (expressively and receptively), which debatably needs cognate awareness (Lemhöfer \& Dijkstra, 2004).

The description of language has been an issue by many linguists for many years. The study of the roots of true cognate and false cognate in European languages is very scarce and negligible till to Persian language which any research has not been done until as far as I know.

Psycholinguists, linguists, and teachers have been interested in errors made by learners of second language, either in their writing or speech, or both. (Persian is a part of the Indo-European group of languages. Indo-European is different families of language and one of the widely spoken in the world. Among others, it comprises the Slavic languages (Russian, Polish, etc.), the Romance languages (French, Spanish, Latin, etc.), the Baltic languages, Celtic languages, Armenian, Albanian, Greek, the Germanic languages (German, English, Swedish, etc.). The subcategory of Indo-European that Persian is one of them is named Indo-Aryan or Indo-Iranian branch.)

The purpose of this study was to state students and teachers' awareness of knowing and using true and false cognate words of first language in second language.

\section{Review of Literature}

There are a large number of natural multi-linguals in many regions of the world. By the way, in economic view through the processes of globalization and migrations, there is a need for lingua franca. In many societies of Europe where the monolingual is used more than multilingual, these tendencies are also strong. In education, culture, social life, and employment, the knowledge of one language is unavoidable (Aronin \& Singleton, 2008; Burkett \& Klein, 2008; Cook, 1993; Graddol, 1997).

In comparison with other parts of the world, in Iran the linguistic map is relatively difficult. So by assuming that the listener/reader is not aware of cross-linguistic similarities, speaker's understanding of language or text from foreign countries should be a problem. Because of the numerous similarities that Persian shares especially on the lexical level, it may cause positive transfer from the native language to the language 
that is supposed to be learned (Keshavarz \& Astaneh, 2004; Talebinejad \& Sarmazeh, 2012).

However, comprehension and production of cognate vocabulary is affected by numerous constraints which are connected with language typology and psych-typology, and also with some individual's differences and the number of languages known.

Cognate awareness is related to a metalinguistic skill in a way that an individual is able to distinguish and maximize the relation between the lexical and conceptual information which is steady cross-linguistically. While children who are typically developed bilingual in comparison to monolingual children show the metalinguistic skill of distinguishing a word from its concept at an earlier age, those who have L1 struggle with executive functions and metalinguistic (Kamhi, 1996; Smith-Lock, 1995).

\section{Elements in Recognizing Cognates}

There are many cognate words in English which can be used in English language teaching classes and these terms should be directly applied by teachers in teaching languages (Kassaian \& Esmae'li, 2011).

As cognate words were emerged in 1997, not only the higher level students vocabulary should increase but also elementary students vocabulary should enhance at a quietly short period of time as well, but as Swan stated in 1997, resemblance among lexical items and availability of cognates words do not always result in increased proficiency of L2 vocabulary.

Keshavarz and Astaneh (2004) pointed that learners unconsciously did not really admit cognate words as equivalent to their own language words even though these words can be a perfect resource for supposing the meaning and keeping in mind new words. Pahlavannezhad and Zadehtavakoli (2013) stated the fact that the only one element which was used in conveying meaning was the actual similarities or dissimilarities of the appearance or form of the words and its meaning. Also the discrimination and judgment of every learner is important.

The student tendency towards the admission of beneficence of learning L2 by using L1 depends on several factors. The three main concepts in understanding why some learners fail to recognize the relationship between their L1 and L2 are psychotypology and language typology, the languages which are utilized, and different personalities of learners.

Typological relationship between languages and psych typological gap is distinguished by learners who are the main principle factors affecting acceptance of cognates relationship between L1 and L2 (Kellerman, 1995). The effect of cross-linguistic between typologically near languages is more powerful such as Polish and Slovak, or Swedish English (Odlin, 2006; Ringbom \& Jarvis, 2009). If the trainer understands both languages, the cross-linguistic influence will increase.

Ringbom (2009) believed the resemblance of language forms and items. If the learner thinks that two languages are too different to have similarities, they would not notice some actual similarities. Odlin (1987) has stated that almost all learners are not aware of cognate words and they do not notice and believe that there are some words which are connected in some aspects. Thus, the learner must first be aware of cognate vocabulary to recognize opportunities for transfer. The awareness of cognates may also depend on the number of languages known or used by the learner.

Many scholars mentioned the differences between monolinguals and multi-linguals in some aspects such as general language awareness, facilitated language learning, language strategies, or metalinguistic awareness (e.g., Cenoz, 2001; Genesee \& Nicoladis, 2007). 
As Singleton and Aronin (2007) state, those multi-linguals are more experienced in the way of learning and using the language. Moreover, they have more linguistic and metalinguistic knowledge, and they can interact with environment more easily.

Also, White and Horst (2012) have stated that more awareness and communication with cross-linguistic similarities will cause a mental model for intercomprehension. It is believed that more awareness can lead bilinguals to be more close to multi-linguals in their competence. Finally, different personalities can be studied in the field of learning cognates. Abilities, propensities, and beliefs are three areas of individuals in learning language as Ellis (2010) mentions.

Contrary to the original hypothesis of Schmidt (1990), Dornyei and Skehan (2009) have stated that although the ability of noticing in every individual is different from the others, strategy training and understanding the self-regulation are important to recognize the importance of cognates in learning L2.

\section{Method}

Three hundred and eighty-five were selected from 3,789 statistical population, 158 of whom were female and the rest of them were male who participated in 2014-2015 school year at three levels of associate's, bachelor's, and master's degrees of Islamic Azad University. They were native speakers of Persian who were studying in term one as well as teachers of English in English educational institutions in Zanjan, Iran. All participants were given a book for their participation in the study. Each educational level was considered as one category with the total sample calculated by using Kokran Formula, and the amount of each category was determined by using appropriate proportion and Randomized Categorical Sampling method. The participants' age was between from 18 to 52, with a mean age of 29 years. The materials were 45 words of recognizing the origin of words (English or Persian), knowing phonological, semantic, or both of them and to be true cognate or false cognate which had been chosen from different dictionaries (Longman Dictionary of Contemporary English, Collins Cobuild English Dictionary, Cambridge International Dictionary of English, and Oxford Advanced Learner's Dictionary) and the Internet; various sources were used in the project for the data collection from 500 words by doing CVR and CVI (Lawshe's table with index of $80 \%$ and $82 \%$ respectively) for being reliable and valid. ANOVA was used for studying the effect of educational level on the rate of awareness. In other words, awareness means have been compared in different educational levels. The results of ANOVA indicated that in all variables except false cognates, there was a significant difference between society awareness levels which was to be studied. By using the following Dankan test in the variance analysis, the hypothesis of zero which is in equivalent groups, is rejected by the help of Dankan, groups are compared two by two in order to indicate the groups which have significant difference. We determine the groups which have significant differences.

\section{Discussion}

There is no significant difference (Root of word in English) between the mean of awareness in A.D. (4.46), B.A. (6.34), and M.A. (6.14) levels, but there is a significant difference between the level of awareness of teachers group (9.33) and the other groups. Root of word in Persian: There is a significant difference between the level of awareness of A.D. (3.60) level and the other groups. There is no significant difference between B.A. (6.92) and M.A. (7.88), but there is a difference between teachers group (11.55) and the other groups. "Not to know the origin of words": There is a significant difference between the level of awareness of A.D. (1.53) level 
and the other groups. There is no significant difference between the level of awareness of B.A. (1.90) and M.A. (2.88), but there is a significant difference between the awareness level of the teachers (4.44) and the other groups. "Semantics": There are insignificant differences between the level of A.D. (9.73), B.A. (11.60), and M.A. (9.89), but compared the level of awareness among the group of teachers (15.11) to other groups, there is significant difference. "Phonology": There is no significant difference between the awareness of the A.D. (14.93) and B.A. (14) and there is insignificant difference between the level of awareness of M.A. (10.22) and teachers (15.22). But between the A.D., M.A. degree, teachers and B.A. with teachers, there are significant differences. "Both of them": There is no significant difference between the level of awareness in A.D. (11.53), B.A. (15.69), M.A. (18.20), and teachers (21.38). There is a significant difference between the A.D. with M.A., A.D. with teachers, and B.A. with teachers. "True cognate": There is no significant difference among groups of the A.D. (19.46), B.A. (20.57) and M.A. (23.44). There is still no significant difference between M.A. and teachers (27.55). "False cognates": Since analysis of variance has been insignificant for this parameter, there is no significant difference between the levels of awareness of the four groups in this regard (2.80-3.42-4.19-6.61 Association degree-Bachelor-Master and Teacher respectively) (see Appendix A).

\section{Conclusion}

Various investigations have shown that the native language impacts foreign word recognition and this influence is adapted by the dexterity in the nonnative language. Words being alike in two or more languages which are called cognates in a number of fields signify an attention-grabbing, illuminating, and crucial facet of the language that is being learned as a second language. The results of this study support the findings of Caselli, Bates, Casadio, Fenson, Fenson, Sanderl, and Weir (1995), and Tréville (1996), which concluded that students do not recognize cognates and, due to this, instructors should teach students how to recognize and work with cognates. As well, to believe that a cognate, only because of having a common root and shared graphics, is an easy word to recognize is to negate that there are multiple differences amongst cognates, and cognate characteristics.

In terms of phonological overlap, the presented ideas have the potential of creating a new and interesting strand of research. Results show that phonology plays an important role while recognizing a written word.

The most important conclusion from this experiment is that target word recognition is significantly influenced by the type of cognate. Likewise, given the pedagogical implications, teachers should not assume that just because cognates are used, students will recognize them. It is important to include more activities focused on word recognition in text-books or language curriculums to train students to identify cognates and use them appropriately. Cognates were also considered as facilitating communication. Being aware of the true cognates or false friends, communication and learning are facilitated. As suggested by the current study, students' problems with false friends could be greatly reduced if teachers paid more attention to a meaningful teaching of these lexical items.

\section{References}

Aronin, L., \& Singleton, D. (2008). Multilingualism as a new linguistic dispensation. International Journal of Multilingualism, $5(1), 1-16$.

Basnight, B. D. M., \& Altarriba, J. (2007). Differences in semantic and translation priming across languages: The role of language direction and language dominance. Memory \& Cognition, 35(5), 953-965.

Bassetti, B., \& Cook, V. (2011). Relating language and cognition: The second language user. Language and Bilingual Cognition, 143-190. 
Bultena, S., Dijkstra, T., \& van Hell, J. G. (2014). Cognate effects in sentence context depend on word class, L2 proficiency, and task. The Quarterly Journal of Experimental Psychology, 67(6), 1214-1241.

Burkett, D., \& Klein, D. (2008, October). Two languages are better than one (for syntactic parsing). In Proceedings of the Conference on Empirical Methods in Natural Language Processing (pp. 877-886). Association for Computational Linguistics.

Casaponsa, A., Antón, E., Pérez, A., \& Duñabeitia, J. A. (2015). Foreign language comprehension achievement: Insights from the cognate facilitation effect. Frontiers in Psychology, 6, 588.

Caselli, M. C., Bates, E., Casadio, P., Fenson, J., Fenson, L., Sanderl, L., \& Weir, J. (1995). A cross-linguistic study of early lexical development. Cognitive Development, 10(2), 159-199.

Cenoz, J. (2001). The effect of linguistic distance, L2 status and age on cross-linguistic influence in third language acquisition. Cross-Linguistic Influence in Third Language Acquisition: Psycholinguistic Perspectives, 111(45), 8-20.

Cook, V. J. (1993). Linguistics and second language acquisition. London: Macmillan.

Comesaña, M., Fraga, I., Moreira, A. J., Frade, C. S., \& Soares, A. P. (2014). Free associate norms for 139 European Portuguese words for children from different age groups. Behavior Research Methods, 46(2), 564-574.

Dijkstra, T., Miwa, K., Brummelhuis, B., Sappelli, M., \& Baayen, H. (2010). How cross-language similarity and task demands affect cognate recognition. Journal of Memory and Language, 62(3), 284-301.

Dörnyei, Z., \& Ushioda, E. (Eds.). (2009). Motivation, language identity and the L2 self(Vol. 36). UK: Multilingual Matters.

Ellis, R. (2010). Second language acquisition, teacher education and language pedagogy. Language Teaching, 43(2), $182-201$.

Ferré, P., Sánchez-Casas, R., \& Guasch, M. (2006). Can a horse be a donkey? Semantic and form interference effects in translation recognition in early and late proficient and non-proficient Spanish-Catalan bilinguals. Language Learning, 56, 571-608.

Genesee, F., \& Nicoladis, E. (2007). Bilingual first language acquisition. Handbook of Language Development, 324-342.

Graddol, D. (1997). The future of English?: A guide to forecasting the popularity of the English language in the 21st century. UK: The English Company (UK) Ltd..

Hall, C. J., Newbrand, D., Ecke, P., Sperr, U., Marchand, V., \& Hayes., L. (2009). Learners' implicit assumptions about syntactic frames in new L3 words: The role of cognates, typological proximity, and L2 status. Language Learning, 59(1), 153-202.

Hojati, A., Roustaei, M., \& Mirzaee, A. (2013). A Study of false friends in English and Farsi. European Journal of Humanities and Social Sciences, 19(1), 951-962.

Kamhi, A. G. (1998). Trying to make sense of developmental language disorders. Language Speech, and Hearing Services in Schools, 29(1), 35-44.

Kassaian, Z., \& Esmae'li, S. (2011). The effect of bilinguality on L3 breadth of vocabulary knowledge and word reading skill. Theory and Practice in Language Studies, 1(8), 966-974.

Kellerman, E. (1995). Crosslinguistic influence: Transfer to nowhere? Annual Review of Applied Linguistics, 15, 125-150.

Kennison, S. M., Fernandez, E. C., \& Bowers, J. M. (2014). The roles of semantic and phonological information in word production: Evidence from Spanish-English bilinguals. Journal of Psycholinguistic Research, 43(2), 105-124.

Keshavarz, M. H., \& Astaneh, H. (2004). The impact of bilinguality on the learning of English vocabulary as a foreign language (L3). International Journal of Bilingual Education and Bilingualism, 7(4), 295-302.

Kroll, J. F., \& Tokowicz, N. (2005). Models of bilingual representation and processing. Handbook of Bilingualism: Psycholinguistic Approaches, 531-553.

Lado, R. (1964). Language teaching: A scientific approach. US: McGraw-Hill Inc..

Lemhöfer, K., \& Dijkstra, T. (2004). Recognizing cognates and interlingual homographs: Effects of code similarity in language-specific and generalized lexicaldecision. MemCognit, 32(4), 533-550. doi: 10.3758/BF03195845

Linck, J. A., Hoshino, N., \& Kroll, J. F. (2008). Cross-language lexical processes and inhibitory control. The Mental Lexicon, 3(3), 349.

Odlin, T. (2006). Could a contrastive analysis ever be complete. Cross-Linguistic Influence in the Second Language Lexicon, 22-35.

Pahlavannezhad, M. R., \& Zadehtavakoli, F. H. (2013). The effect of semantic features of native lexical items on Persian speaking learners of English in translation. Language in India, 13, 195-210.

Peeters, D., Dijkstra, T., \& Grainger, J. (2013). The representation and processing of identical cognates by late bilinguals: RT and ERP effects. J Mem Lang, 68(4), 315-332. doi: 10.1016/j.jml.2012.12.003

Ringbom, H., \& Jarvis, S. (2009). The importance of cross-linguistic similarity in foreign language learning. The Handbook of Language Teaching, 106-118. 
Schmidt, R. W. (1995). The role of consciousness in second language learning. Applied linguistics, 11(2), 129-158.

Skehan, P. (2009). Modeling second language performance: Integrating complexity, accuracy, fluency, and lexis. Applied Linguistics, 30(4), 510-532.

Sunderman, G., \& Kroll, J. F. (2006). First language activation during second language lexical processing: An investigation of lexical form, meaning, and grammatical class. Studies in Second Language Acquisition, 28, 387-422.

Talebinejad, M. R., \& Sarmazeh, A. N. (2012). Comparative investigation of Persian's cognates and false friends with some IE languages. Theory and Practice in Language Studies, 2(7), 1477-1484.

Treville, M. C. (1996). Lexical learning and reading in L2 at the beginner level: The advantage of cognates. Canadian Modern Language Review, 53(1), 173-90.

White, J. L., \& Horst, M. (2012). Cognate awareness-raising in late childhood: Teachable and useful. Language Awareness, 21(1-2), 181-196.

\section{Appendix A}

Table A1

Investigating of Influence of the Educational Level on the Rate of Awareness Based on ANOVA

\begin{tabular}{|c|c|c|c|c|c|c|}
\hline Test result & Sig & Volume F & Mean & Number & Educational level & Variable \\
\hline \multirow{4}{*}{ significant } & \multirow{4}{*}{0.002} & \multirow{4}{*}{4.89} & 4.46 & 15 & Association of art & \multirow{4}{*}{ Root of word in English } \\
\hline & & & 6.34 & 135 & bachelor & \\
\hline & & & 6.14 & 217 & master & \\
\hline & & & 9.33 & 18 & teacher & \\
\hline \multirow{4}{*}{ significant } & \multirow{4}{*}{0.000} & \multirow{4}{*}{7.68} & 3.60 & 15 & Association of art & \multirow{4}{*}{ Root of word in Farsi } \\
\hline & & & 6.92 & 135 & bachelor & \\
\hline & & & 7.88 & 217 & master & \\
\hline & & & 11.55 & 18 & teacher & \\
\hline \multirow{4}{*}{ significant } & \multirow{4}{*}{0.000} & \multirow{4}{*}{9.29} & 1.53 & 15 & Association of art & \multirow{4}{*}{ I do not know } \\
\hline & & & 1.90 & 135 & bachelor & \\
\hline & & & 2.88 & 217 & master & \\
\hline & & & 4.44 & 18 & teacher & \\
\hline \multirow{4}{*}{ significant } & \multirow{4}{*}{0.009} & \multirow{4}{*}{3.88} & 9.73 & 15 & Association of art & \multirow{4}{*}{ Semantic } \\
\hline & & & 11.60 & 135 & bachelor & \\
\hline & & & 9.89 & 217 & master & \\
\hline & & & 15.11 & 18 & teacher & \\
\hline \multirow{4}{*}{ significant } & \multirow{4}{*}{0.000} & \multirow{4}{*}{7.72} & 14.93 & 15 & Association of art & \multirow{4}{*}{ Phonology } \\
\hline & & & 14.00 & 135 & bachelor & \\
\hline & & & 10.22 & 217 & master & \\
\hline & & & 15.22 & 18 & teacher & \\
\hline \multirow{4}{*}{ significant } & \multirow{4}{*}{0.001} & \multirow{4}{*}{21.38} & 11.53 & 15 & Association of art & \multirow{4}{*}{ Both of them } \\
\hline & & & 15.69 & 135 & bachelor & \\
\hline & & & 18.20 & 217 & master & \\
\hline & & & 21.38 & 18 & teacher & \\
\hline \multirow{4}{*}{ significant } & \multirow{4}{*}{0.000} & \multirow{4}{*}{23.44} & 19.46 & 15 & Association of art & \multirow{4}{*}{ True cognate } \\
\hline & & & 20.57 & 135 & bachelor & \\
\hline & & & 23.44 & 217 & master & \\
\hline & & & 27.55 & 18 & teacher & \\
\hline \multirow{4}{*}{ insignificant } & & & 2.80 & 15 & Association of art & \\
\hline & 0138 & 184 & 3.42 & 135 & bachelor & False cornate \\
\hline & 0.150 & 1.04 & 4.19 & 217 & master & r dise cogilate \\
\hline & & & 6.61 & 18 & teacher & \\
\hline
\end{tabular}


Table A2

Results of T Test for Comparing Observed Mean With Expected One

\begin{tabular}{llllllll}
\hline Significant & Sig & Quantity T & SD & Sample Mean & Expected score & Number & Variable \\
\hline significant & 0.000 & 43.28 & 3.94 & 6.30 & 15 & 385 & Root of word in English \\
significant & 0.000 & 54.21 & 5.22 & 7.55 & 22 & 385 & Root of word in Farsi \\
significant & 0.000 & 43.07 & 2.47 & 2.56 & 8 & 385 & I don't know \\
significant & 0.000 & 75.41 & 7.35 & 10.73 & 39 & 385 & Semantic \\
significant & 0.000 & 63.34 & 8.37 & 11.96 & 39 & 385 & Phonology \\
significant & 0.000 & 6.15 & 8.88 & 17.21 & 20 & 385 & Both \\
significant & 0.000 & 34.41 & 8.27 & 22.47 & 37 & 385 & True cognate \\
significant & 0.000 & 21.64 & 3.72 & 3.89 & 8 & 385 & False cognate \\
\hline
\end{tabular}

